\title{
On the Economics of Renewable Energy Sources
}

\author{
Prepared for a Special Issue in Energy Economics, edited by \\ Carlos de Miguel, Alberto Gago, Xavier Labandeira and Baltasar Manzano \\ Ottmar Edenhofer ${ }^{1, a, b, c}$, Lion Hirth ${ }^{\text {a,d }}$, Brigitte Knopf a , Michael Pahle a , \\ Steffen Schlömer ${ }^{\text {a }}$, Eva Schmid ${ }^{\text {a }}$, Falko Ueckerdt ${ }^{\text {a }}$ \\ a Potsdam Institute for Climate Impact Research, P.O. Box 601203, 14412 Potsdam, Germany \\ ${ }^{b}$ Chair Economics of Climate Change, Technische Universität Berlin, Straße des 17. Juni 145 \\ 10623 Berlin, Germany \\ ${ }^{c}$ Mercator Research Institute on Global Commons and Climate Change, Torgauer Straße 12-15 \\ 10829 Berlin, Germany \\ ${ }^{d}$ Vattenfall GmbH, Chausseestraße 23, 10961 Berlin, Germany \\ JEL: Q21, Q28, Q42, Q54, Q55, D47
}

\begin{abstract}
With the global expansion of renewable energy (RE) technologies, the provision of optimal RE policy packages becomes an important task. We review pivotal aspects regarding the economics of renewables that are relevant to the design of an optimal RE policy, many of which are to date unresolved. We do so from three interrelated perspectives that a meaningful public policy framework for inquiry must take into account. First, we explore different social objectives justifying the deployment of RE technologies and review model-based estimates of the economic potential of RE technologies, i.e. their socially optimal deployment level. Second, we address pivotal market failures that arise in the course of implementing the economic potential of RE sources in decentralized markets. Third, we discuss multiple policy instruments curing these market failures. Our framework reveals the requirements for an assessment of the relevant options for real-world decision makers in the field of RE policies. This review makes it clear that there are remaining white areas on the knowledge map concerning consistent and socially optimal RE policies.
\end{abstract}

Keywords: Energy, mitigation, integrated assessment modeling, variable renewables, electricity market design, renewable policy

\footnotetext{
${ }^{1}$ Corresponding author, Tel.: +49 331288 2565, Fax: +49 331288 2570, Email: ottmar.edenhofer@pik-potsdam.de (Ottmar Edenhofer). All other authors are listed in alphabetical order. Email: lion.hirth@vattenfall.de (Lion Hirth), knopf@pik-potsdam.de (Brigitte Knopf), michael.pahle@pik-potsdam.de (Michael Pahle), steffen.schloemer@pikpotsdam.de (Steffen Schlömer), eva.schmid@pik-potsdam.de (Eva Schmid), ueckerdt@pik-potsdam.de (Falko Ueckerdt).
} 


\section{Introduction and Motivation}

The use of renewable energy $(\mathrm{RE})$ sources has grown rapidly in recent years. Approximately half of the electricity-generating capacity installed globally between 2008-2009 draws on RE sources (IPCC, 2011). Although RE supplied $16.7 \%$ of final global energy consumption in 2010-split evenly between traditional biomass and modern RE-fossil fuels still provided the lion's share at $80.6 \%$, with the final $2.7 \%$ being generated by nuclear power (REN21, 2012). Yet, for all sectors of the energy-system a large variety of technically viable RE solutions have been developed that are theoretically capable of substituting fossil-fuel-based technologies. Recent assessments indicate that the technical potential of RE sources, i.e. the amount of RE output obtainable through the full implementation of demonstrated technologies or practices, is substantially higher than global energy demand (IPCC, 2011). The technical potential therefore does not limit the accelerated use of RE sources; however, it is a poor indicator for the net social benefits of the deployment of RE technologies. The metric is hence not capable of guiding the policy-maker with regard to the design of an optimal RE policy, which becomes ever more urgent as renewables leave the status of a niche market in many countries.

In order to assess the future role of RE, a richer analytical framework is needed. A subset of the technical potential that addresses the policy-relevant questions of technology choice, location and timing is the economic potential of RE sources. It constitutes the socially optimal benchmark deployment level of RE technologies when all corresponding social costs and benefits, including negative externalities and cobenefits, are taken into account (Moomaw et al., 2011). By definition, the economic potential is not only a function of techno-economic assumptions, e.g. expectations on technology learning, but hinges crucially on the prioritization of underlying and potentially competing public policy objectives. In order to determine the global economic potential of RE sources, the starting point is to choose a particular weighting of public policy objectives based on value judgments, i.e. a social welfare function, used for the evaluation of climate and energy policies. Climate change mitigation, energy security, green jobs, green growth, reduced local environmental damages and poverty reduction are potential public policy objectives highlighted by decision makers that can, in principle, justify the deployment of RE technologies as a means to an end. In economic language, the economic potential is referred to as the welfare-optimal deployment level.

The decentralized market solution generated by decentralized agents like firms, consumers and investors that do not take into account relevant multiple externalities of their actions, e.g. climate damages, technological spillovers, security standards, etc., cannot be expected to yield the welfareoptimal quantity of RE deployment. That is, in the presence of market failures (arising when externalities of decentralized actions impede the fulfillment of multiple public policy objectives) the market potential of RE sources attains a lower level of welfare than the economic potential (Figure 1). Such a setting, with multiple externalities, requires a careful analysis of the multiple policy instruments curing these market failures. A meaningful public policy framework for inquiry must take into account the interrelated triplet of (i) multiple public policy objectives, (ii) multiple externalities, i.e. market failures, and (iii) multiple policy instruments (Edenhofer et al., forthcoming). 


\section{Economic Potential:}

$\rightarrow$ Socially (welfare-) optimal benchmark; considers all social costs, benefits, negative externalities and cobenefits

$\rightarrow$ Depends on multiple objectives

\section{Market Potential:}

$\rightarrow$ Decentralized solution

$\rightarrow$ Depends on multiple market failures and multiple policy instruments

Figure 1. The market potential of RE sources as a subset of the economic potential with respect to social costs and benefits, i.e. welfare. Own illustration, based on Verbruggen et al. (2011).

For designing an optimal RE policy (one that steers the market solution towards the welfare-optimal benchmark), the policymaker requires knowledge of the welfare-optimal deployment level, the nature, dynamics and causality of system effects that cause multiple market failures, as well as those of policy instruments intended to incentivize agents on the market towards the welfare-optimal benchmark. Besides that many of these aspects are to date unresolved, available literature treats the different aspects inherent to the economics of renewables in a rather disjunctive manner. The economic potential is subject to analysis in the integrated assessment community by means of complex, numerical integrated assessment models (IAMs). Externalities, market failures and policy instruments are generally investigated using empirical methods and analytical models within a different community. The fragmented literature and the lack of a consistent framework prevent a concise assessment of the different policy options. Therefore, our aim is to bring these perspectives together.

In this paper, we review pivotal aspects of the economics of renewables that are relevant to the design of an optimal RE policy. We do so by adopting the three perspectives emerging from the public policy framework described above, leading to the following guiding research questions. Which public policy objectives can justify the deployment of RE technologies? What are current assessments of the economic potential of RE sources and how robust are they? Which pivotal market failures need to be addressed in the course of implementing the economic potential of RE in decentralized markets, and which kinds of policy interventions are adequate? The contribution of this paper is twofold. We discuss the available literature with regard to these research questions and identify knowledge gaps. At the same time, the analysis describes the requirements for an assessment of the relevant options for the expansion of RE technologies that real-world decision makers might have.

The paper is structured as follows. Section 2 discusses the multiple public policy objectives that can potentially justify the increased deployment of technologies drawing on RE sources. Section 3 explores and evaluates the available literature assessing the global economic potential of RE sources. It further provides a brief review on the economics of variability of RE sources. Section 4 then turns to the market perspective and reflects on the question of which pivotal market failures need to be addressed in order to fulfill the economic potential, i.e. the integration of RE technologies into the market, and by means of which policy instruments to achieve this. Finally, Section 5 summarizes and concludes.

\section{Multiple Public Policy Objectives for Renewables}


Asserting that the deployment of RE technologies is not an end in itself raises the question of which public policy objectives can potentially justify the increased deployment. In the past, the main argument for policy intervention intended to foster and develop RE sources is to avoid climate externalities of fossil fuel use. However, in recent years other policy objectives have become increasingly important in the public debate and it is frequently argued that the deployment of RE technologies is beneficial due to its associated cobenefits, i.e. physical positive side-effects (Edenhofer et al., forthcoming). This Section examines how RE can contribute to the achievement of public policy objectives other than climate change mitigation, including energy security, green jobs, green growth, reduction of local environmental damages, poverty reduction and other sustainability concerns.

In its broadest sense, energy security refers to the uninterrupted provision of vital energy services (GEA, 2012 , p.27) or, in other words, robustness against sudden disruptions of energy supply (Arvizu et al., 2011, p.120). Important energy security concerns are hence the availability and distribution of resources and the variability and reliability of the energy supply (IPCC, 2011, p.47). This can be measured, for example, by reduced global interdependence via reduced import/export balances or increased diversity and resilience of the energy supply (GEA, 2012, p.6). For many industrialized countries the key energy security challenge is the dependence on imported fossil fuels, particularly oil. A sudden rise in oil prices may disrupt the economy of oil importers, for whom reduced oil imports may be beneficial. Yet, it seems that the potential for RE to reduce oil imports, of which the transport sector demands the largest share, is limited. In past scenario analyses RE solutions for the transport sector, e.g. biofuels or the electrification of the transport sector, have not played a dominant role (Arvizu et al., 2011, p.127ff). It should be noted, though, that biofuels and the electrification of the transport and heating sectors are not fully represented in current IAMs (cf. Table S2.1 in Luderer et al., forthcoming). In the electricity and heating sector, RE have the potential to substitute coal and gas, but where there are large domestic resources, such as in the US, the substitution by RE has little impact on energy security. Therefore, the comparative advantage of RE lies in its environmental benefits rather than in its potential to increase energy security (Borenstein, 2012). An increasing share of variable and unpredictable RE in the electricity sector may even have an adverse effect on energy security if no appropriate measures to assure a constant and reliable supply are undertaken, which is particularly challenging in developing countries (Arvizu et al., 2011). McCollum et al. (2011; 2013) calculate that policy costs can be reduced if energy security and climate change mitigation are targeted simultaneously. However, energy security in this study is measured by an indicator that accounts for diversity in primary energy carriers and import dependence and the effect of increasing RE is solely to reduce imports and a larger diversity of energy carriers. It is unclear if the proposition that climate mitigation through an increased share of RE has positive synergies for increasing energy security once the variability of RE is taken into account properly.

The green job argument, i.e. that subsidizing RE deployment stimulates job creation, is an important justification for green fiscal stimulus packages (Borenstein, 2012) and their large up-front investment costs. However, RE subsidies must be compared with other policy instruments that push the economy towards its capacity frontier. These short-term welfare comparisons of different policy instruments have not been carried out in reliable studies. Some economists expect the long-term impact of green jobs to be quite favorable because of the impact on the domestic economy. The empirical foundation for this 
claim is ambiguous. For example, Germany quadrupled its solar PV installations from 2008-2010, but panel manufacturing in Germany has declined from $77 \%$ of new installed capacities in 2008 to $27 \%$ in 2010 due to massive investments in China and Taiwan (Borenstein, 2012). Some proponents of RE argue that RE systems are favorable because they are more labor-intensive than conventional energy systems. Yet, this indicator provides no justification even if additional jobs are created. RE should only be subsidized if their social returns on investment are (i) higher than their private returns on investment and at the same time (ii) lower than investments in other technologies. Without an explicit reference to the social return on investment any kind of job creation could be justified, irrespective of its social value.

The green growth argument is also popular; investments in RE technology deployment are claimed to be a driving force behind long-term GDP growth and decreasing emissions. Since economic growth is related to other social objectives such as wellbeing, job creation, and tax revenues, the green growth strategy is perceived as a typical win-win strategy, as pointed out by a recent UNEP report (UNEP, 2011). Despite that, there is a risk when RE policy is seen as an alternative to carbon pricing due to political feasibility constraints, e.g. in case of the EU ETS that is currently perceived as a failure due to the lack of long-term price signals to induce large investments in low-carbon technologies. In contrast to a suboptimal carbon price, a policy that boosts RE technology deployment through direct subsidies may yield a fast breakthrough in technology learning at low costs, ensuring that RE becomes the dominant technology (Farmer and Trancik, 2007). Various studies have estimated the costs of such technology policies as a substitute to carbon prices (i.e. Palmer and Burtraw, 2005; i.e. Fischer and Newell, 2008). However, these papers assume rather marginal emission reductions for a short time horizon (up to two or three decades) and neglect the supply-side response of fossil resource owners. It can be shown that RE subsidies as a substitute for optimal carbon pricing are an extremely expensive option. Kalkuhl et al. (2013) report remarkably higher mitigation costs due to the supply-side response of fossil resource owners. If governments only use RE subsidies to reduce emissions without carbon pricing, RE will become cheaper than fossil resources. Resource owners will respond by reducing the scarcity rent component of the fossil resource price, which will allow them to continue extracting at positive, albeit lower, profits. To achieve the emissions target, the regulator has to raise subsidies further until RE prices fall below the extraction costs of fossil resources. The result of this race to the bottom of energy prices is an explosion in energy use. Mitigation is achieved with wasteful RE use, which makes this policy option so costly. A RE technology policy may be a temporary option to replace carbon pricing, if carbon pricing remains infeasible. This would make carbon pricing at a later stage less costly than it would be without any technology policy (Kalkuhl et al., 2013).

Unless energy prices are increased through carbon pricing or other energy taxes, the achievement of long-term climate targets solely through RE subsidies would hence be very costly. The hope that investments in RE will boost economic growth while reducing emissions is based on a flawed understanding of the supply-side dynamics of fossil fuels. Green growth may have some political merits because it provides a new narrative; investment in RE can internalize the climate externality because carbon pricing seems to be a politically infeasible option. Nevertheless, this narrative can become dangerous if fossil fuel owners and suppliers of RE have an incentive to form a coalition against carbon pricing due to the favorable rent distribution. From a normative point of view, carbon pricing is an 
indispensable option for a realistic climate and energy policy, but it should be accompanied by policy instruments to address the specific externalities of RE (cf Section 5.1).

Moreover, RE have the potential to reduce local environmental damages from fossil fuel extraction, e.g. environmental degradation arising from mountain-top mining, coal mining in South America and Australia, or the negative impacts from tar sands extraction in Canada. Further, the reduction of local air pollution and associated health concerns from phasing out the burning of fossil fuels could be a cobenefit of RE use through the avoidance of local emissions of particulate matter (PM), nitrous oxide (NOx), sulfur dioxide, and non-methane volatile organic compounds (Sathaye et al., 2011). It should be noted that additional welfare effects of cobenefits can conceptually only occur in a so-called secondbest setting, that is when these local externalities have not been addressed by appropriate policy instruments. This is true in many world regions. For example, in China there is need for low-cost and low-water-intensive flue gas desulfurization, NOx, and PM removal technologies (You and Xu, 2010).

Regarding poverty reduction and other sustainability concerns, RE can contribute to social and economic development due to their scalability and independence from continuous fuel supply - particularly in remote and poor rural areas lacking centralized energy access. This makes them well-suited for remote regions not serviced by large infrastructure. In particular, RE can help to accelerate the access to energy for the 1.4 billion people in the world without access to electricity and the additional 1.3 billion using traditional biomass (IPCC, 2011). The transition to modern energy access, which is influenced by income levels, requires a progression from traditional to more modern devices and fuels that are more environmentally benign with fewer negative health impacts (IPCC, 2011). RE enable decentralized access to affordable, modern energy sources and cleaner cooking, which generates multiple benefits (GEA, 2012); by providing better lighting, heating, and cooling services, access to modern energy carriers can improve education and school attendance. Cleaner cooking is an effective tool for improving health through reduced exposure to household air pollution, particularly for woman and children (GEA, 2012). It can also help combat hunger by increasing food productivity and reducing post-harvest losses.

For the public policy objectives energy security, green growth, and green jobs there is, to date, only a little convincing in depth literature that analyzes the existence of additional externalities beyond the climate and technology innovation externality. One exception is McCollum et al. (2011; 2013), who calculate that the policy objectives of energy security, reduced air pollution, health, and climate change mitigation result in substantial synergies that lead to proportionally lower policy costs if all policy objectives are tackled holistically. However, such synergies or cobenefits can conceptually induce welfare implications only if market or government failures exist and are not fully addressed by dedicated policy instruments and/or in case synergetic policy instruments are cheaper than the piecemeal achievement of individual public policy objectives (Edenhofer et al., forthcoming). Additional research is required to shed more light on this widely unknown territory of attributing cobenefits of RE technology deployment in a framework that acknowledges multiple public policy objectives as well as multiple externalities. In the following sections, we therefore focus on climate change as the main argument for RE policy intervention.

\section{The Macro-Economics of Renewable Energy Sources}


What are current assessments of the economic potential of RE sources and how robust are they? The common methodological approach for estimating the economic potential is to perform a scenario analysis with large-scale IAMs. They (i) are able to capture many of the key interactions within the energy system as well as the economic and the climate system, (ii) have a basis in economics in the sense that they use economic criteria for endogenous model decisions, (iii) have a long-term temporal and multi-regional spatial scale, and (iv) include the policy levers necessary to enforce mitigation (Krey and Clarke, 2011). The scenarios focus on the policy objective of greenhouse gas (GHG) mitigation, which means they prescribe a GHG stabilization level that is to be achieved in the long-term future. Scenarios that have no constraint on GHG emissions are referred to as baseline scenarios. Comparing economic activity measures (e.g., macro-economic consumption) of baseline and mitigation scenarios allows determining the social costs of mitigation. One can further asses the role of RE sources, i.e. their option value, by comparing the social costs of mitigation under different assumptions of RE deployment. The following reviews (Section 3.1) and evaluates (Section 3.2) state-of-the art estimates of the economic potential of RE sources. As particularly for the electricity sector the variable renewables wind and solar are assessed to play an important role, the Section wraps up with a brief reflection on the economics of variability (Section 3.3).

\subsection{Estimates of the Economic Potential of RE Sources in Mitigation Scenarios}

In order to provide robust insights into the role of RE sources in climate change mitigation, the IPCC Special Report on Renewable Energy Sources and Climate Change Mitigation (SRREN) reviewed 164 mitigation scenarios that were collected through an open call and were generated by 16 different IAMs (Fischedick et al., 2011). The majority of scenarios was developed in the course of three model intercomparison projects: (i) the Energy Modeling Forum (EMF) round 22 (Clarke et al., 2009), (ii) the Adaptation and Mitigation Strategies (ADAM) project (Knopf et al., 2009; Edenhofer et al., 2010), and (iii) the Report on Energy and Climate Policy in Europe (RECIPE) (Edenhofer et al., 2009; Tavoni et al., 2012). All of these 164 scenarios have time horizons spanning from 2005 until at least 2050 or up to 2100. While one third assumes an idealized world in which all technologies are available and where full global participation is achieved, two thirds of the scenarios consider optimal policies under the restrictions imposed by a potential technology failure or delayed participation. In the latter scenarios, constraints render the mitigation effort more difficult, adding an important aspect to the debate around the feasibility of low-stabilization scenarios (Knopf et al., 2011).

The estimates for the aggregate economic potential of RE sources determined by the 164 scenarios are illustrated in Figure 2, in relation to their respective $\mathrm{CO}_{2}$ emissions for the years 2030 and 2050. A first noteworthy feature of Figure 2 is that there are multiple efficient pathways to achieve low-stabilization targets as indicated by the spread of the green dots representing the low-stabilization scenarios. This holds both in terms of emission trajectories over time and the magnitude of their economic potential. Second, the economic potential of RE sources increases with the stringency of the mitigation target, particularly in the long-term - even though the ranges within groups of stabilization scenarios indicated by the color coding are rather wide. Third, comparing baseline scenarios, indicated in black, with the status quo of 2007, indicated by the cross, reveals that RE sources are used beyond current levels even if there is no constraint on future $\mathrm{CO}_{2}$ emissions. Overall, one can conclude from this scenario analysis that 
RE should play an important role in climate change mitigation. However, it is important to acknowledge the substantial uncertainty regarding estimates of the absolute economic potential of RE sources.

2030

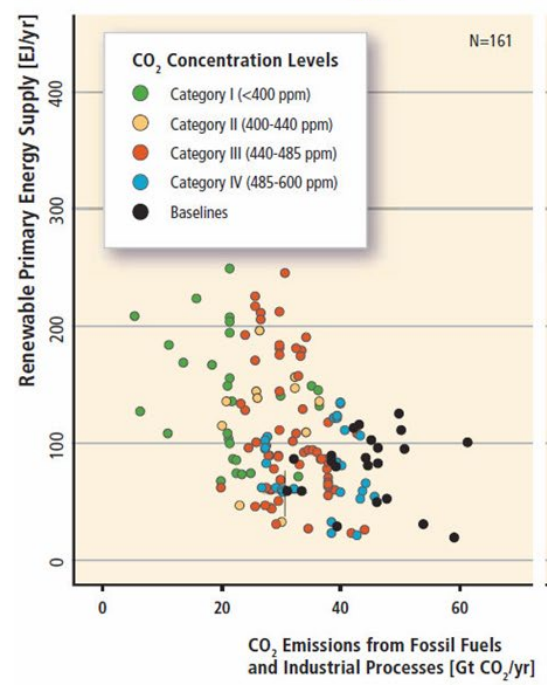

$\mathrm{N}=161$

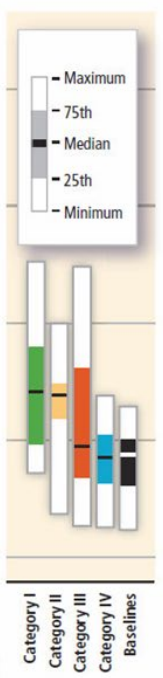

2050

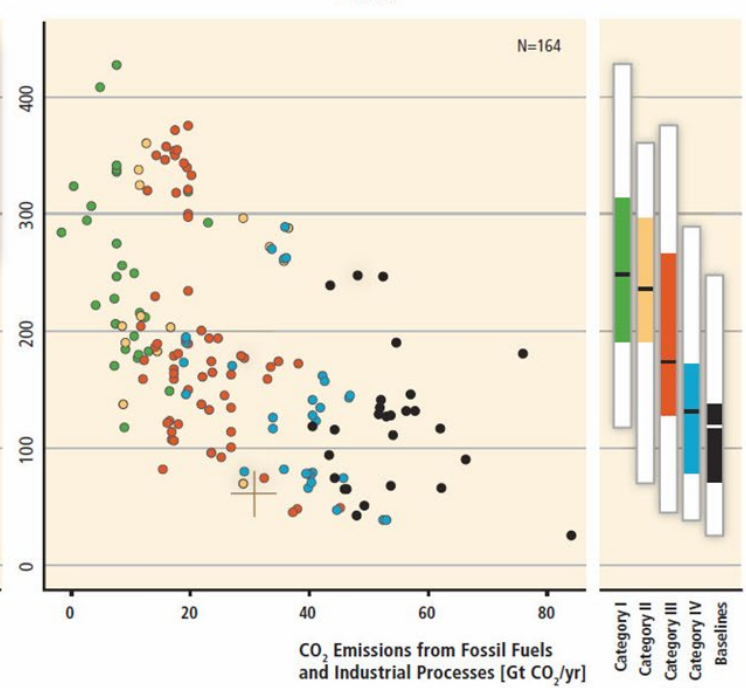

Figure 2. Estimates of the economic potential of RE sources in terms of global renewable primary energy supply (direct equivalent) plotted against $\mathrm{CO}_{2}$ emissions from fossil fuels and industrial processes from 161 and 164 model-based, long-term mitigation scenarios in the years 2030 and 2050 for different mitigation scenarios and the baseline, respectively. Crosses indicate the relationship in 2007. Source: Figure SMP.9 in IPCC (2011).

Figure 3 indicates that the large spreads in scenario results found for the aggregate estimates of the economic potential also occur for individual RE sources in 2050. Note that the direct equivalent method leads to a bias in this Figure 3 as bioenergy is accounted for prior to conversion; if the primary equivalent method was used, the other energy sources' bars would be three times larger (Fischedick et al., 2011). Despite the wide range of estimates, bioenergy accounts for a substantial share of the RE supply in 2050 in all scenarios, and particularly so in the Non-Annex I countries. For the latter, the share of traditional biomass continuously decreases in all the scenarios, being replaced with modern biomass in the long-term (assuming the availability of second-generation biofuels). The role of geothermal energy is rather limited in all scenarios and with a relatively low spread. This is also the case for hydropower. The remaining RE sources, wind and solar, play an important role despite that their distributions are again rather spread out, particularly regarding solar in Non-Annex I countries. Since both wind and direct solar energy are primarily used for generating electricity, their share in the electricity supply is illustrated in Figure 4. As with bioenergy, the median of the distribution across scenarios rises with the stringency of the mitigation target, yet it remains below $20 \%$ in the lowstabilization scenarios in 2050. Again, the distributions are wide, extending from a minimum of virtually zero to a maximum share of $\mathbf{7 0 \%}$ in $\mathbf{2 0 5 0}$ in the case of low stabilization. Luderer et al. (forthcoming) find that in the EMF 27 model comparison project, half of the models report electricity shares from wind and solar greater than $40 \%$ after 2050 in the medium- and low-stabilization scenarios. 


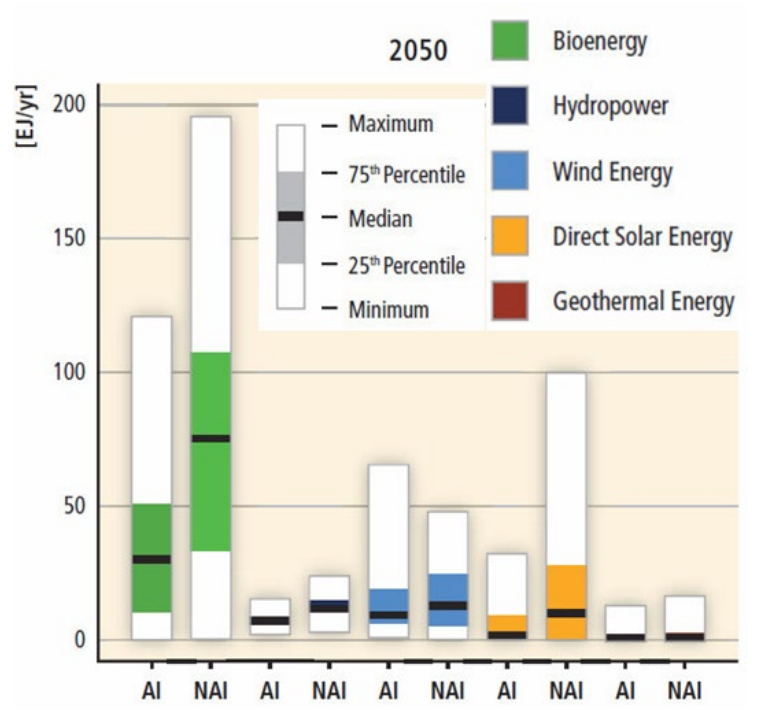

Figure 3. Distribution of global primary energy supply (direct equivalent) in Annex I (AI) and Non-Annex I (NAI) countries by source, across all scenarios for the year 2050. Based on Figure 10.8 in Fischedick et al. (2011).

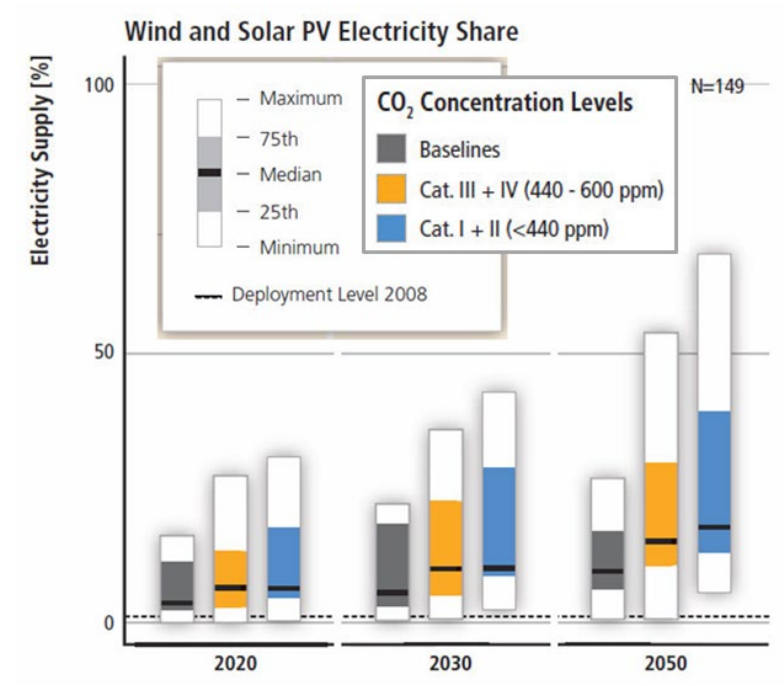

Figure 4. Share of wind and solar photovoltaic (PV) in electricity production in different mitigation scenarios. Based on Figure 10.9 in Fischedick et al. (2011).

Figure 5 indicates the social costs of mitigation for a subset of the 164 scenarios, namely those resulting from the RECIPE project (Luderer et al., 2012). It depicts aggregated global consumption losses between 2005-2100 determined by three different IAMs, and for scenarios with different technology availability assumptions. The measure indicates how much economic activity is foregone due to investment in mitigation. Comparing the technology constrained scenarios shows that limiting RE deployment to baseline level ("Fix RE") doubles the costs in two of the three models (WITCH and ReMIND-R) compared to the default case with full technology availability. In these two models, RE have the largest influence on the costs. In the third model (IMACLIM-R), CCS availability is much more important. This difference arises mainly from structural uncertainty about the economic system, as reflected by the different modeling approaches and their underlying assumptions (Luderer et al., 2012). 


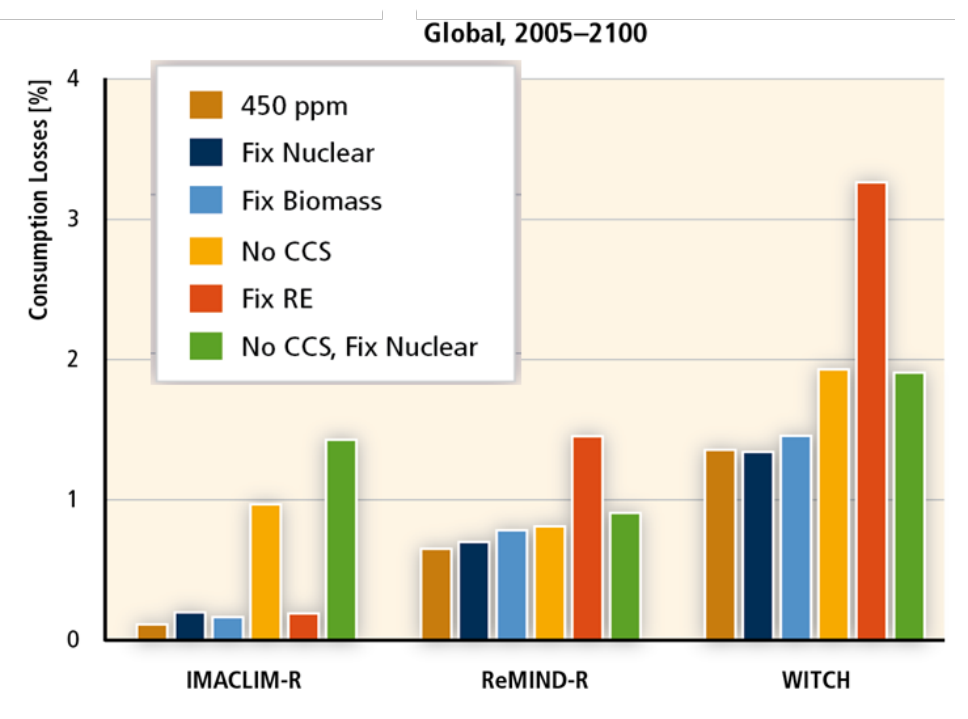

Figure 5. Aggregated global consumption losses from 2005-2100 relative to the respective baseline scenarios in the RECIPE project. The numbers are given for the default setting of $450 \mathrm{ppm}$ with full technology availability, as well as for scenarios with only limited availability of technologies. The discount rate is 3\%. Source: Based on Figure 10.12 in Fischedick et al. (2011).

While the above analysis considers the global perspective, a number of scenarios have been developed specifically for Europe over the recent years. In the "Energy Roadmap 2050", the European Commission (2011) launched a debate on how to develop a long-term framework for climate and energy policies in Europe, including a strategy aimed at an $80 \%$ reduction in GHG emissions by 2050 . The Energy Roadmap concludes that several different strategies can be used to achieve decarbonization in Europe, all of which indicate that RE will "rise substantially" (European Commission, 2011, p.7). This is confirmed in a recent model comparison exercise (EMF 28) by Knopf et al. (2013), which shows that RE will become the dominant energy carrier by 2050 along with the remaining fossil fuels. Similar to the global scale, bioenergy will be the most important source of RE, while in the electricity sector, wind will become the most important source of low-carbon energy. Interestingly, Pahle et al. (2012) find that at the global scale, solar photovoltaic (PV) plays a dominant role for scenarios with $80 \%-100 \%$ RE in the electricity sector. The importance of solar PV varies strongly across regions. In Europe, both onshore and offshore wind are dominant technologies, while in Germany, offshore wind is dominant in scenarios that reach $100 \%$ of RE electricity supply. This is confirmed by a more detailed meta-analysis of German transformation pathways (Schmid et al., forthcoming). Finally, Mai et al. (2012) examined a scenario with an $80 \%$ share of RE in the electricity sector in the US and found that nearly $50 \%$ was derived from wind and solar PV generation.

\subsection{Evaluation of Mitigation Scenarios}

The major finding from the analysis of current state-of-the art mitigation scenarios in Section 3.1 is that estimates of the future economic potential of RE sources on a global and regional scale are significantly 
higher than today's deployment levels. However, the range of estimates is very wide, which indicates a substantial amount of uncertainty. For a given mitigation target, economic potential estimates depend on the one hand on specific scenario assumptions and on the other hand on differences in the structural formulation of individual IAMs. For low stabilization scenarios the availability and performance of nonRE low-carbon technologies and the development of global energy service demand are important drivers that are not harmonized across scenarios (Fischedick et al., 2011). For baseline scenarios particularly assumptions on the future costs of fossil-fuel extraction are important. The impacts of different scenario assumptions are straightforward in a ceteris paribus sense; higher energy service demand, higher fossil fuel prices, lower investment costs of RE technologies and higher investment costs of non-RE technologies each induce a higher economic potential of RE sources. A dedicated discussion on the drivers behind differing IAM results is provided e.g. in Luderer et al. (2012; forthcoming) or Mai et al. (2013). Specifically with respect to the use of RE sources, it is necessary to be aware of two structural properties in the formulation of the IAMs used to generate the results in Section 3.1: first, they generally neglect to explicitly account for other public policy targets than climate mitigation, e.g. sustainability, as well as for corresponding negative externalities, which is particularly problematic for biomass. Second, the crude geographical and temporal resolution of IAMs leads to problems in adequately representing system effects of variability inherent to renewable electricity generation.

Regarding the first issue, Creutzig et al. (2012b) conclude that the key trade-off between emissions savings from bioenergy and emissions production by induced land use change is only partially represented in the models considered in the SRREN. In particular, the models neglect to consider the negative trade-offs between bioenergy exploitation and water availability, food security, soil quality, biodiversity, and subsistence farming. Therefore, the economic potential of bioenergy identified in the mitigation scenarios could be much lower once additional public policy objectives or social, environmental, or economic constraints are taken into account (Creutzig et al., 2012b). In order to resolve these questions, the ability of IAMs to explicitly integrate key interactions between the energy and land use sectors must improve. This refinement may reduce inherent structural uncertainties and would constitute a first step towards a more coherent analysis of bioenergy potential. The SRREN argues that the economic potential of bioenergy depends on preconditions that can be shaped by land use management and agricultural, water, and bio-fuel policies (Chum et al., 2011; Creutzig et al., 2012a; Creutzig et al., 2012b). Therefore, the regulatory uncertainty determining these preconditions could play a major role in assessing the economic potential of bioenergy.

While fossil, nuclear ${ }^{3}$, and hydro plants are dispatchable electricity generators, wind and solar power are variable generators, because their output is subject to variable weather conditions (also known as intermittent, fluctuating, or non-dispatchable). The literature has identified temporal variability, uncertainty, and the fact that they are bound to certain locations as key properties of variable

\footnotetext{
${ }^{3}$ Technically, nuclear power can be dispatched on a quite wide range of load levels, similar to hard coal plants. This is regularly done in systems with large shares of nuclear power, such as France and Japan. On other systems, regulation sometimes prevents free dispatch. However, the main reason for nuclear to run mostly baseload is economic, not technical.
} 
renewables (Milligan et al., 2011; Sims et al., 2011; Borenstein, 2012). Renewable technologies are sometimes compared along these dimensions (cf. Sims et al., 2011, Table 8.1).

However, due to numerical constraints, IAMs cannot provide the temporal and spatial resolution required to explicitly represent variability in the electricity sector. Their typical time resolution is in steps of 5-10 years, while electricity consumption, wind speeds, and solar radiation feature relevant variability on all time scales of minutes to years. IAMs also model regions as large as Europe as a whole, while representing transmission explicitly requires a resolution on the scale of ten kilometers. Many models use stylized formulations to account for variability, however, most of these approaches lack welfare-theoretical rigor. As a consequence, these approximations reduce the robustness of model results and increase the uncertainty in estimating the economic potential of RE. In particular, ignoring variability underestimates the costs of variable renewables in the electricity sector, especially at high penetration rates.

While some models - mostly older versions of IAMs - ignore variability altogether and thus generate results that are biased towards optimistic cost estimates, today most IAMs apply some sort of stylized formulation to represent the challenges of variability. Of the 17 models reviewed by Luderer et al. (forthcoming), two ignore variability completely, while the other models take variability into account. For example, they limit the maximum share of variable renewables, add an "integration cost" penalty, or require storage or back-up capacity. The most basic approach is to limit the generation share of wind and solar to, e.g., 15\% (seven models). However, this implicitly assumes infinite integration costs at higher shares, which is an extreme assumption. Such hard constraints are price-insensitive and ignore the possibility for system adjustments even under strong economic pressure. A more balanced approach is the introduction of a cost penalty per generated unit of variable renewable electricity that might increase with its penetration (four models). Other models require the provision of specific technology options to foster the integration of variable renewables, like gas-fired backup capacities or electricity storage (eight models). Some models represent load variability with a load duration curve (six models). Sullivan et al. (2013) propose a "flexibility constraint" to account for variability. However, all these approaches have three limitations. First, the foundations and completeness of the approaches is unclear. Often motivated from a technical perspective, they lack a clear relation to the economic costs of variability. Second, each approach focuses on specific aspects of variability while omitting others. Finally, these stylized representations are difficult to parameterize.

\subsection{The Economics of Variability}

In most IAMs, the equation that balances power demand with supply is characterized by average annual values due to their coarse resolution. Hereby, IAMs treat electricity as a homogenous good, which means that power supply from different fuels and technologies is perfectly substitutable. More precisely, all technologies are implicitly assumed to provide electricity with the same temporal and spatial characteristics. As a consequence, in such a model, the attractiveness and optimal quantities of generating technologies are simply determined by their levelized costs of electricity (LCOE). LCOE are the average specific generation costs, or, more precisely, the discounted life-time fixed and variable cost of a generation technology in $€ / M W h$. 
However, as Joskow (2011) argues, the LCOE is a flawed metric for comparing the economic attractiveness of variable renewables with dispatchable generation technologies such as fossil, nuclear, or hydro plants. ${ }^{4}$ The main reason for this that Joskow puts forward is the non-homogeneity of electricity in time: because electricity prices vary, the revenue of power form variable renewables depends on the time at which it is produced. To assess the economic attractiveness of different technologies the LCOE of a technology needs to be compared with its marginal economic value. It should be added that the marginal value of a generation technology is not only affected by timing of production, but also by the location and with respect to the uncertainty under which it is produced (Hirth 2012, Ueckerdt et al. 2013). Hence, comparing the LCOE of different generation technologies has little welfare-economic meaning. Similar shortcomings apply to a second widespread metric that is used assess generation technologies economically, the grid parity. It is usually defined as the point where LCOE of wind or solar power fall below the average retail electricity price. As LCOE, this concept ignores the temporal and spatial structure and forecast errors of generation. Furthermore, it often ignores the fact that grid fees and taxes comprise a large share of retail prices.

To overcome the limitations of these metrics and to improve IAMs it is essential to evaluate generation technologies, in particular variable renewables, on a system level. There are two literature branches, which unfortunately are hardly connected, analyzing the system impacts of variability. On the one hand, a significant body of literature quantifies "integration costs" that are associated with different aspects of variability (Gross et al., 2006; Smith et al., 2007; Milligan and Kirby, 2009; DeCesaro and Porter, 2009; GE Energy, 2010; Holttinen et al., 2011). However, this literature lacks approaches to incorporate their results into economic modeling and does not provide a consistent economic interpretation in the public policy debate. On the other hand, a second branch of literature analyses wind and solar variability by estimating their marginal economic value (Lamont, 2008; Borenstein, 2008; Fripp and Wiser, 2008; Nicolosi, 2012a; Mills and Wiser, 2012; Hirth, 2013). Studies typically find decreasing values of variable renewables with increasing penetration. While these analyses tend to be less detailed than integration costs studies their key merit is the provided link to welfare-theory: the optimal share of a generation technology is given by the interception of its marginal economic value and its generation costs (LCOE). Approaches to represent variable renewables appropriately in IAMs should build on these two branches of literature in order to provide more meaningful estimates of the economic potential of variable renewables sources to policymakers (Ueckerdt et al., 2013). However, a concise interpretation requires a unified framework, which to date is not provided in literature.

\section{Market Integration of Renewable Energy Sources}

The last Section dealt with issues related to the economic potential of RE sources, i.e. the socially optimal benchmark, and established that RE technologies play an important role in combating climate change and in achieving other social objectives. This Section turns towards the market potential of RE sources, i.e. the decentralized market solution generated by decentralized agents. An urgent question in

\footnotetext{
${ }^{4}$ Joskow was not the first to recognize this point. See Lamont (2008), Borenstein (2008) and Fripp and Wiser (2008) for earlier expositions in the context of variable renewables. Investment decisions in liberalized power markets have been based on market value ever since these markets existed. Implicitly, it was considered even before (Stoughton et al. 1980).
} 
this context is how to bring and integrate RE technologies into the market. In particular, the following questions regarding the integration of RE are important. Are there market failures specific to RE that prevent them from exploiting their full economic potential and, if so, which policy instruments are necessary to alleviate them (Section 4.1)? Furthermore, what are the implications of the rising proportion of renewables for the design of power markets (Section 4.2)? These are the questions that need to be answered when turning from model-based energy scenarios to instrument and market designs for sustainable power systems.

\subsection{Market Failures and Subsidy Schemes for the Innovation and Diffusion of Renewables}

In the context of RE, there are two fundamental market failures discussed in the literature that may motivate policy intervention: (i) climate externalities and (ii) technological externalities in the energy market (Jaffe et al., 2005). They call for two separate policy instruments - one for each externality when a first-best optimum should be achieved and when the interaction between policy instruments can be ignored; the latter clearly is a strong assumption. Most importantly for the wide-ranging debate on this issue, given that technology externalities indeed exist and are relevant, is the implication that additional technology policies are needed to complement carbon pricing. This section will make a case for technology externalities and thus an additional support instrument for RE. As a starting point it is helpful to categorize the externalities according to where they occur in the development stages of a technology: invention, innovation, and diffusion.

Invention and innovation failures are caused by underinvestment in basic research and development (R\&D). Insufficient invention and innovation arises due to spillovers and is a general problem for all kinds of technologies. While many economists agree with this general theoretical argument, they are reluctant to recommend RE-specific supply-side technology policies mainly for two reasons. First, it is unclear whether the gap between the social and private return on investment of RE technologies is unusually high compared to other sectors of the economy. This is especially difficult to assess because of the high uncertainty associated with technological forecasts in the energy sector (Farmer and Trancik, 2007). Second, as long as property rights are well defined, spillovers may be kept at bay. As a result, Nordhaus (2009a) advises the introduction of technological- and sector-neutral policies, such as patents, which may address both concerns. However, there are empirical arguments that demonstrate why intellectual property rights are insufficient in the sense that the investment returns that innovators receive are relatively low. Reasons include the mobility of engineers between firms, publicly financed research programs, and spillovers caused by direct foreign investment (Irwin and Klenow, 1994). Therefore, patent laws should be complemented by other policy instruments on the supply-side such as subsidies for basic R\&D investment. Most economists would probably consent to this.

It is less straightforward to identify market failures in the diffusion and adoption phase of RE technologies, which require demand-side subsidy schemes such as feed-in-tariffs and or production subsidies for correction; compare Table 2 in Gillingham and Sweeney (2010). A first group of market failures is associated with "dynamic increasing returns", which may be caused by learning-by-using, learning-by-doing, or network externalities (Jaffe et al., 2005). In fact, there is some empirical evidence that learning-by-doing is the process underlying reductions in specific investment costs, which can be 
observed with increasing installed capacities (Neij, 2008; Junginger et al., 2010). However, learning-bydoing as such does not justify subsidies for renewables when no spillover effects occur and the gained knowledge is appropriated by the learning firm. However, there is some evidence that learning-by-doing creates spillover effects because the products and processes will eventually spread across firms in the RE sector (Braun et al., 2010; Piscitello et al., 2012). Admittedly, there is also empirical evidence that significant learning-by-doing is rather rare and uncertainties regarding the specification of the learning curve are substantial (Nemet, 2009; Nordhaus, 2009b; Yeh and Rubin, 2012).

A second market failure is related to the completeness of markets. Stiglitz (1990, p.19) points out that "in the absence of future markets the price system cannot perform its essential coordinating role with respect to future-oriented activities such as investments". Since the lifetimes of energy infrastructures are typically in the order of 20-30 years, the existence of long-term markets is quintessential. However, in the case of electricity for example, future trading hardly spans more than a few years. Accordingly, this failure makes the strongest case for a demand-side promotion scheme, as only such instruments can create a long-term market environment that is appropriately able to coordinate and trigger investments.

The existence of market failures in combination with other conditions that prevail in the power market may also lead to technological lock-in, which is another reason to support RES. In a recent study, Kalkuhl et al. (2012) analyze this issue using a general equilibrium framework that arises from the interplay of the following factors: i) spillover effects at the diffusion stage that cannot be captured by individual firms (see above), ii) the homogeneity of electricity ${ }^{5}$, which fails to create niche markets of sufficient size to induce economies of scale, and iii) accruing investment risks due to uncertainty about the stringency of future mitigation targets, which discourages learning technologies in favor of non-learning technologies. The latter factors, ii) and iii), will be described in the following.

The homogeneity of electricity: in general, the imperfect substitutability of new innovative products due to variety-loving consumers is one important reason why consumers purchase recent innovations, be it smart phones, high definition flat screens, or tablet PCs, even when waiting for a few months would allow consumers to save money. The love of variety is one important driver for the diffusion of new products in highly dynamic sectors of the economy because it allows for the creation of protected niche markets without policy intervention. However, this strategy is not applicable to the energy sector due to the homogeneity of the product from a customer's perspective. Therefore, it is argued that a technology-specific policy is of higher importance in the energy sector than in other sectors.

Risk premium on learning technologies: intertemporally efficient mitigation requires perfect commitment to optimal emissions caps or carbon taxes by governments in the near- and long-term. In general, imperfect commitment leads to suboptimal investment in the energy sector (Ulph and Ulph, 2009), which can be cured by investment subsidies for clean energy. Learning technologies suffer more from risk premiums than non-learning technologies due to imperfect commitment since an investment

\footnotetext{
${ }^{5}$ As explained in Section 3.3, electricity is a homogenous good for a specific time and location. The degree of homogeneity in this context refers to the ability and willingness of consumers to distinguish between green and conventional electricity.
} 
in knowledge capital is required in addition to investment in the physical product. Therefore, even perfect anticipation of learning-by-doing can lead to suboptimal investment if uncertainty about future climate policies is high. Kalkuhl et al. (2012) find that for a critical parameter constellation of learning rates and energy generation costs, small spillovers can have a substantial effect on the energy mix and on mitigation costs due to long-lasting lock-ins into dynamically inferior low-carbon technologies. This effect is accelerated when a high degree of homogeneity in the electricity sector prohibits the creation of niche markets. Based on this result, it can be argued that subsidies for the diffusion of RE technologies are justified if a low-cost equilibrium can be attained.

The above study (Kalkuhl et al. 2012) also compares different subsidy schemes such as feed-in-tariffs, quotas, and the taxation of non-learning technologies: for a discussion of these instruments see Greene and Yatchew (2012). In doing so, it assumes that the regulator knows all the relevant parameters of the diffusion externality and can, therefore, fully anticipate the cost-reduction potential of RE technologies. However, in reality, regulators have to take into account information asymmetries about learning rates, risk premiums, etc. Only when uncertainty and information asymmetries are modeled explicitly can the advantages and costs of different options for policy instruments be compared. Therefore, Kalkuhl et al. (2012) have applied a rudimentary risk analysis by calculating welfare losses when the government anticipates an incorrect learning rate. It turns out that, on average, a flawed subsidy scheme is better than no subsidy at all.

To conclude, we pointed out two reasons - market failures and technology lock-in - why technology and climate externalities require at least two policy instruments, i.e., a subsidy scheme for RE technologies in addition to carbon pricing. From our point of view it is of particular relevance in this respect that even small intertemporal spillovers can create lock-in effects toward non-learning technologies.

Finally, notwithstanding all the arguments in its favor, the case for subsidizing renewables cannot be upheld indefinitely. As Hausmann and Rodrik (2003) have suggested, the design of reasonable RE policy resembles the design of industry policy. Therefore, they argue for a carrot-and-stick strategy. The carrot strategy includes subsidies for R\&D, even during the diffusion process. Economic policy may also encourage venture capital. This policy has to be complemented by a stick strategy, which defines clear criteria for phasing out bad projects according to well-defined performance standards (Rodrik, 2007, p.106). As Rodrik convincingly argues, "the main task of a government is not to pick the winner, but to know the losers" (Rodrik, 2007, p.107). It seems that Rodrik's two principles for successful industry policy are highly relevant for RE policy (Rodrik, 2007, pp. 114-116) . First, there must be a built-in "sunset clause," which defines clear ex-ante cut-off conditions for subsidies, i.e. once RE technologies no longer exhibit learning-by-doing and spillover effects, subsidies must be phased out because they can no longer be justified. This is also in line with Gillingham and Sweeney (2010): "the optimal correction for failures that decrease in magnitude and eventually vanish over time would be a transient intervention". Second, public support must target activities rather than sectors or firms. In particular, subsidies for integration options could be an investment in new activities with a high social return on investment.

\subsection{Renewables and Reliability: The Limits of Short-Term Marginal Cost Pricing}


The second important issue regarding market integration of RE concerns the role of the price signal in the efficient coordination of dispatch and investment. When there is a large share of RE in the market, the current market design based on short-term marginal costs results in prices that often amount to zero because most RE are generated at approximately zero marginal costs. In fact, the price-reducing effect of renewables has already become apparent in markets with high penetration rates like in Germany, where this phenomenon was termed "merit order effect of RE" (Sensfuß et al., 2008). Against this background, some observers are concerned that short-term marginal pricing will not be an appropriate design for future markets with a large proportion of RE. Their concerns are that the average price in such a market will fall below long-run average costs of RE capacity used. This would prevent these technologies from coming into the market in the first place. Leprich et al. (2012) argue that under such conditions, RE investments would not be able to recover capital costs and would after all not be realized.

Upon closer inspection however, this "problem" both disregards the dynamic response and the overall competitiveness (i.e. efficient share) of RE in the market. As far as the dynamic response is concerned, lower average prices caused by higher RE penetration lead to a reduction of overall capacity, which in turn increases the frequency of scarcity events and respective scarcity prices. According to theory this will bring the market back to the long-term equilibrium in which long-run average costs and average revenues are balanced for all capacities and where, as direct result, the capacity level is efficient; see for example Stoft (2002). Clearly, prices in such an ideal market would not be as uniformly distributed as they are today; as indicated, there would be many hours in the year with low or zero prices, but also hours with relatively high scarcity prices. But this is only a reason for concern if additional market failures or imperfections arise out of this more extreme distribution of prices (see below). The question arises whether a large proportion of RE can actually be competitive in the market? If this is not the case, then RE cannot be sustained by the market irrespective of the distribution of prices, because by definition the market provides the efficient capacity level and technology mix. Accordingly, when a high proportion of RE is a political target rather than a market outcome, straightforward economics suggests that inefficient RE capacities cannot recover capital costs and will require additional subsidies, for example in the form of a support scheme. So it may be true that some RE will not recover their capital costs, but this is not because short-run pricing is inappropriate.

While the more extreme and volatile prices of a high RE market share are not a reason to expect the current design to fail per se, they are linked to another issue of liberalized electricity markets, namely a potential mismatch in cost recovery with marginal generation prices; see Pérez-Arriaga and Meseguer (1997) for an early investigation. More recently this issues has become known as the "missing money problem" (Cramton and Stoft, 2006). It states that in a market where electricity is the sole commodity traded ("energy-only market"), several market imperfections as well as flawed regulatory rules can be identified to lead to insufficient incentives to build new capacity. In turn, generation capacity is inadequate and the market fails to reliably provide electricity. There is a continous debate about whether the "missing money problem" actually arises in current energy-only markets (cf. Müsgens and Peek, 2011; Nicolosi, 2012b) and if so what the right approach would be to tackle this problem (cf. Perez-Arriaga, 2001; Hogan, 2005; Joskow, 2006; Cramton and Stoft, 2006; Rodilla and Batlle, 2010; 
Cramton and Ockenfels 2012). In accordance with the diversity of belief or distrust in energy-only market mechanisms found in the literature, the suggested approaches range from "doingnothing/market-solves-the-problem" (Müsgens and Peek, 2011; Nicolosi, 2012b), to "remedy-flawedintervention/energy-only" (Hogan 2005) to "capacity-parket or -payment" approaches (Cramton and Stoft, 2006; Joskow, 2006; Cramton and Ockenfels, 2012).

Assuming that the "missing money problem" exists, investigating whether and how renewables affect it requires a closer look at its causes. Cramton and Ockenfels (2012) have compiled the various market failures and imperfections that may give rise to it.
a) Absence of demand response.
b) Spot prices are too low to pay for adequate capacity when capacity is adequate.
c) Spot prices are unlikely to be optimal during scarcity events due to market power.
d) Spot prices are unlikely to be optimal during scarcity events due to regulatory intervention.
e) Price volatility and risks.
f) Coordination failures.

In general, all of these failures and imperfections are generic and do not depend on the particular technologies in the power mix. The absence of a full demand-response is the most significant of these market failures. Due to technological constraints the majority of customers usually cannot react to the price signal in real time. During extremely tight market situations, when current demand exceeds current available generation capacity by far, this circumstance may result in involuntary load shedding to sustain system stability (Stoft, 2002). Cramton and Ockenfels (2012, p.116) consider this from the opposite perspective: "an electricity market with sufficient demand elasticity always clears". If this were the case, the market could still suffer from "missing money", but it would not pose a reliability problem. Due to these demand-side flaws, "generation adequacy" and the according reserve margin have to be determined administratively (Cramton and Stoft, 2006). Hence, given the non-existence of sufficient demand response, "missing money" may indeed be a problem in the sense that actual capacity investments do not comply with exogenously determined capacity levels presumably required for system stability. The possible causes are threefold. First, it could arise from the non-optimality of spot prices at scarcity events. This may happen when regulators set a cap on prices. The main reason for doing so is that in times when supply is tight, high prices could reflect both scarcity in the market and the exertion of market power. In other words, it is difficult to determine whether the market is short on capacity or long on generators withholding capacity to raise prices. Consequently, prices may not reach the optimal level that is necessary to trigger sufficient investments for generation adequacy. Second, at any time when generation capacity is adequate, spot prices would be too low to uphold the respective capacity level. This is because the marginal plant that covers peak demand in the market cannot recover its fixed costs, because-in theory-it sells to the market at no more than its marginal short-run costs. Third, there are additional shortcomings on the side of investors irrespective of market design issues. Investors may be risk-averse and be deterred from investments due to prices volatility and risks. Moreover, they may interact strategically, through which the coordination of investments can be 
hampered. These behavioral flaws may also lead to the under-provision of new capacities, which in turn threatens generation adequacy.

The rapid expansion of renewables exacerbates the particular conditions and situations in which the above market failures and imperfections arise in at least two ways. First, rising price volatility may discourage investors or require a significant risk premium for investments beyond the level prevailing in traditional markets (Joskow, 2006). Second, decreasing average prices make investment in new plants less attractive and induce early closures of old plants. This creates an additional strain on the reserve margin and is bound to result in a higher frequency of scarcity events. Since spot prices during such events are likely to be suboptimal (see above), a market with a high proportion of renewables is more prone to experience a "missing money problem", resulting in decreased reliability. In addition, it is open to speculation how the more atomistic market structure usually associated with renewables would affect the coordination failure.

To counteract what regulators perceive to be the "missing money problem", capacity mechanisms have been set up in several markets worldwide and are being frequently discussed. The UK has already initiated the preparatory processes while France and Germany are experiencing heated debates concerning whether, when, and how to implement such a mechanism; for an overview of the various proposals in Germany see Flinkerbusch and Scheffer (2012). Clearly, the ongoing expansion of renewables makes the implementation of such mechanisms more urgent. Drawing on the German experience, it is clear that this aspect will become important for future debates on RE integration as well as for future research. A key question for the design of a capacity mechanism that is compatible with a high proportion of renewables will be how it interacts with other market instruments such as carbon pricing and RE support schemes, and how variable renewables may create greater reliability given their demand-independent load profile.

\section{Summary and Conclusion}

On a global scale, the deployment of RE sources has grown rapidly in recent years, leaving the status of a niche market in many countries. In this paper, we reviewed pivotal aspects related to the economics of renewables for the design of an optimal RE policy. The analysis was guided by an integrated public policy framework that brings together a welfare-theoretic perspective (economic potential) with the perspective of a decentralized market solution that takes into account multiple market failures and multiple policy instruments (market potential). Both perspectives give rise to a variety of knowledge gaps that require dedicated future research.

The starting point for analyzing the economics of renewables is a clarification of which public policy objectives can be achieved by means of an increasing deployment of RE technologies. Section 2 revealed that in addition to the objective of substituting fossil energy carriers to achieve climate change mitigation, RE can in principle be justified by multiple objectives like energy security, green jobs, green growth, reduced local environmental damages and poverty reduction. However, the discussion showed that only a little in depth literature exists that analyzes the existence of additional externalities beyond climate and technology innovation. Also, it is largely unclear to what extent welfare effects of RE 
deployment induced by one policy objective will occur with respect to externalities impeding the attainment of a second policy objective. It is hence worthwhile to further explore the attribution of cobenefits of RE technology deployment in a multi-objective framework in future research. Also, it would be helpful to better understand the policies by which trade-offs between multiple objectives for RE deployment could be reconciled.

As regards the question of which role RE might play in the future, Section 3 has shown that, to date, estimates of the economic potential are predominantly pursued by means of IAMs that focus on the public policy objective of climate change mitigation. These assessments indicate that the economic potential of RE sources both on a global and regional scale is significantly higher than today's deployment levels, particularly for biomass and the variable renewable sources wind and solar. However, the range of estimates is very wide, indicating substantial uncertainty, stemming both from scenario assumptions and structural model formulations. Due to their crude temporal and spatial resolution, IAMs are not able to take into account of the variability of wind and solar, which is especially relevant to the integration challenges arising in the electricity sector. Without an adequate representation of these effects, IAMs are likely to give biased estimates of the economic potential of RE sources. Improving the representation of electricity sector variability in future modeling exercises is thus a major challenge for the IAM community.

Section 4 addressed the question of how to bring and integrate RE technologies into the market. A first finding is that there are several reasons to assume that an additional technology externality exists, which may justify dedicated support for renewables. This is of particular relevance in the climate change context where many economists argue that a price on carbon alone is sufficient and mitigation should be technology neutral. However, the identified market failures are transient and vanish over time.

Accordingly, support should eventually be phased out, at best with a preset "sunset clause" that defines clear-cut criteria from the start. While support schemes are already implemented in many countries, there is still need for further research, especially with regard to the quantification of the technology externality and how to properly define and implement sunset criteria from a political economy point of view.

A second finding in Section 4 concerns the short-run marginal cost pricing design of power markets. Even though some people are skeptical that such a design is suitable when there is a high share of RES, because of the price reducing merit order effect, there are no apparent reasons to assume that it will fail. However, the more extreme prices and higher price volatility that arise when the proportion of RES is high may exacerbate the "missing money problem". Consequently, increasing shares of RE make the implementation of such mechanisms more urgent, and probably also require more sophisticated market designs. Clearly, our inspection of this issue was just preliminary; its complexity requires more rigorous investigation and quantitative analysis. This is a major strand for further research on the economics of renewables.

This review on the economics of renewables not only revealed knowledge gaps but at the same time the requirements for an assessment of the relevant options that real-world decision makers might have. To this end, IAMs should include multiple social objectives in their analysis in order to identify potential 
synergies or even cobenefits between these goals. This particularly implies a better representation of sustainable development mechanisms in the integrated models, e.g. concerning the effects of bioenergy use. In order to provide more accurate estimates of the economic potential of RE sources as a benchmark level for the policy maker, the IAM community has to adequately include and assess the variability of RE in their models. In addition, the evaluation of multiple externalities in a second-best setting will become a crucial challenge when energy policy in general and RE policy in particular gains additional public attention and becomes a contentious issue. It is a shared intuition between economists that multiple externalities require multiple policy instruments. The interaction between different policy instruments (like the impact of RE subsidies on prices at the carbon markets) becomes crucial for the design of public policy packages, contributing to increased complexity. Future research should focus more on such interactions because real-world decision makers are after all challenged by these effects.

Ultimately, a scientific assessment should identify different pathways to achieve social objectives for real-world decision makers. This paper has identified crucial remaining white areas on the knowledge map, despite the growing literature in this field. There is a realistic hope that future research will fill these gaps, allowing real-world decision makers to navigate in a landscape with many emerging hindrances. 


\section{References}

Arvizu, D., T. Bruckner, H. Chum, O. Edenhofer, S. Estefen, A. Faaij, M. Fischedick, G. Hansen, G. Hiriart, O. Hohmeyer, K. G. T. Hollands, J. Huckerby, S. Kadner, Å. Killingtveit, A. Kumar, A. Lewis, O. Lucon, P. Matschoss, L. Maurice, M. Mirza, C. Mitchell, W. Moomaw, J. Moreira, L. J. Nilsson, J. Nyboer, R. Pichs-Madruga, J. Sathaye, J. Sawin, R. Schaeffer, T. Schei, S. Schlömer, K. Seyboth, R. Sims, G. Sinden, Y. Sokona, C. von Stechow, J. Steckel, A. Verbruggen, R. Wiser, F. Yamba and T. Zwickel (2011). Technical Summary. In: IPCC Special Report on Renewable Energy Sources and Climate Change Mitigation. O. Edenhofer, R. Pichs-Madruga, Y. Sokona, K. Seyboth, P. Matschoss, S. Kadner, T. Zwickel, P. Eickemeier, G. Hansen, S. Schlömer and C. v. Stechow, Eds. Cambridge, United Kingdom and New York, NY, USA., Cambridge University Press, Cambridge, United Kingdom and New York, NY, USA.

Borenstein, S. (2008). "The Market Value and Cost of Solar Photovoltaic Electricity Production", CSEM Working Paper 176.

Borenstein, S. (2012). "The Private and Public Economics of Renewable Electricity Generation." Journal of Economic Perspectives 26(1): 67-92.

Braun, F. G., J. Schmidt-Ehmcke and P. Zloczysti (2010). Innovative Activity in Wind and Solar Technology: Empirical Evidence on Knowledge Spillovers Using Patent Data. DIW Berlin Discussion Paper No. 993 http://papers.ssrn.com/sol3/papers.cfm?abstract_id=1633875

Chum, H., A. Faaij, J. Moreira, G. Berndes, P. Dhamija, H. Dong, B. Gabrielle, A. Goss Eng, W. Lucht, M. Mapako, O. Masera Cerutti, T. McIntyre, T. Minowa and K. Pingoud (2011). Bioenergy. In: IPCC Special Report on Renewable Energy Sources and Climate Change Mitigation O. Edenhofer, R. Pichs-Madruga, Y. Sokona, K. Seyboth, P. Matschoss, S. Kadner, T. Zwickel, P. Eickemeier, G. Hansen, S. Schlömer and C. v. Stechow, Eds. Cambridge University Press, Cambridge, United Kingdom and New York, NY, USA.

Clarke, L., C. Böhringer and T. F. Rutherford, Eds. (2009). International, U.S. and E.U. Climate Change Control Scenarios: Results from EMF 22 [Special Issue]. Enegy Economics 31 (Supplement 2):S63S306.

Cramton, P. and A. Ockenfels (2012). "Economics and Design of Capacity Markets for the Power Sector." Zeitschrift für Energiewirtschaft 36: 113-134.

Cramton, P. and S. Stoft (2006). The Convergence of Market Designs for Adequate Generating Capacity. http://www.cramton.umd.edu/papers2005-2009/cramton-stoft-market-design-for-resourceadequacy.pdf

Creutzig, F., A. Popp, R. Plevin, G. Luderer, J. Minx and O. Edenhofer (2012a). "Reconciling top-down and bottom-up modeling on future bioenergy deployment." Nature Climate Change 2: 320-327.

Creutzig, F., C. D. K. von Stechow, C. Hunsberger, N. Bauer, A. Popp and O. Edenhofer (2012b). "Can bioenergy assessments deliver?" Economics of Energy and Environmental Policy 1(2): 65-82

DeCesaro, J. and K. Porter (2009). "Wind Energy and Power System Operations: A Review of Wind Integration Studies to Date", NREL Subcontract Report SR-550-47256.

Edenhofer, O., C. Carraro, J.-C. Hourcade, K. Neuhoff, G. Luderer, C. Flachsland, M. Jakob, A. Popp, J. Steckel, J. Strohschein, N. Bauer, S. Brunner, M. Leimbach, H. Lotze-Campen, V. Bosetti, E. d. Cian, M. Tavoni, O. Sassi, H. Waisman, R. Crassous-Doerfler, S. Monjon, S. Dröge, H. v. Essen, P. d. Río and A. Türk (2009). RECIPE - The Economics of Decarbonization. Synthesis Report.

Edenhofer, O., B. Knopf, T. Barker, L. Baumstark, E. Bellevrat, B. Chateau, P. Criqui, M. Isaac, A. Kitous, S. Kypreos, M. Leimbach, K. Lessmann, B. Magné, S. Scrieciu, H. Turton and D. P. van Vuuren (2010). "The economics of low stabilization: model comparison of mitigation strategies and costs." The Energy Journal 31(Special Issue 1). 
Edenhofer, O., K. Seyboth, F. Creutzig and S. Schloemer (forthcoming). "On the Sustainability of Renewable Energy Sources." Annual Review of Environment and Resources.

European Commission (2011). COMMUNICATION: Energy Roadmap 2050. http://eurlex.europa.eu/LexUriServ/LexUriServ.do?uri=COM:2011:0885:FIN:EN:PDF

Farmer, J. D. and J. E. Trancik (2007). Dynamics of technological development in the energy sector. London Accord Final Publication, J-P Onstwedder and M Mainelli eds.; and Santa Fe Institute Working Paper \#07-12-046

Fischedick, M., R. Schaeffer, A. Adedoyin, M. Akai, T. Bruckner, L. Clarke, V. Krey, I. Savolainen, S. Teske, D. Ürge-Vorsatz and R. Wright (2011). Mitigation Potential and Costs. In: IPCC Special Report on Renewable Energy Sources and Climate Change Mitigation. O. Edenhofer, R. Pichs-Madruga, Y. Sokona, K. Seyboth, P. Matschoss, S. Kadner, T. Zwickel, P. Eickemeier, G. Hansen, S. Schlömer and C. v. Stechow, Eds. Cambridge University Press, Cambridge, United Kingdom and New York, NY, USA.

Fischer, C. and R. G. Newell (2008). "Environmental and technology policies for climate mitigation." Journal of Environmental Economics and Management 55(2): 142-162.

Flinkerbusch, K. and F. Scheffer (2012). "Eine Bewertung verschiedener Kapazitätsmechanismen für den deutschen Strommarkt." Zeitschrift für Energiewirtschaft October.

Fripp, M. and R. H. Wiser (2008). "Effects of Temporal Wind Patterns in the value of wind-generated Electricity in California and the Northwest." IEEE Transactions on Power Systems 23(2): 477 - 48.

GE Energy (2010). "Western Wind and Solar Integration Study" NREL Subcontract Report SR-550-47434. GEA (2012). Summary for Policymakers. In: Global Energy Assessment (GEA). T. B. Johansson, N. Nakicenovic, A. Patwardhan and L. Gomez-Echeverri, Eds. Cambridge, New York, Melbourne, Madrid, Cape Town, Singapore, São Paulo, Delhi, Mexico City, Cambridge University Press.

Gillingham, K. and J. Sweeney (2010). Market Failure and the Structure of Externalities. In: Harnessing Renewable Energy in Electric Power Systems: Theory, Practice, Policy. B. Moselle, R.

Schmalensee and J. Padilla, Eds., RFF Press.

Greene, R. and A. Yatchew (2012). "Support Schemes for Renewable Energy: An Economic Analysis." Economics of Energy \& Environmental Policy 1(2).

Gross, R., P. Heptonstall, D. Anderson, T. Green, M. Leach and J. Skea (2006). The Costs and Impacts of Intermittency: An assessment of the evidence on the costs and impacts of intermittent generation on the British electricity network. www.uwig.org/mwginternal/de5fs23hu73ds/progress?id=Gxdlkw+rOn.

Hausmann, R. and D. Rodrik (2003). "Economic development as self-discovery." Journal of Development Economics 72(2): 603-633.

Hirth, L. (2012a). Integration Costs and the Value of Wind Power. Thoughts on a valuation framework for variable renewable electricity sources. USAEE Working Paper 12-150. http://ssrn.com/abstract=2187632

Hirth, L. (2012b). "The Optimal Share of Variable Renewables", USAEE Working Paper 2054073.

Hirth, L. (2013). "The market value of variable renewables: The effect of solar wind power variability on their relative price." Energy Economics 38: 218-236. http://www.sciencedirect.com/science/article/pii/S0140988313000285

Hogan, W. W. (2005). "On an "ENERGY ONLY" electricity market design for resource adequacy." Working Paper. Center for Business and Government John F. Kennedy School of Government Harvard University Cambridge, Massachusetts 02138.

Holttinen, H., P. Meibom, A. Orths, B. Lange, M. O'Malley, J. O. Tande, A. Estanqueiro, E. Gomez, L. Söder, G. Strbac, J. C. Smith and F. van Hulle (2011). "Impacts of Large Amounts of Wind Power on Design and Operation of Power Systems, Results of IEA Collaboration." Wind Energy 14(2): 179-192. 
IPCC (2007). Summary for Policymakers. In: Climate Change 2007: The Physical Science Basis. Contribution of Working Group I to the Fourth Assessment Report of the Intergovernmental Panel on Climate Change. S. Solomon, D. Qin, M. Manning, Z. Chen, M. Marquis, K. B. Averyt, M. Tignor and H. L. Miller, Eds. Cambridge, United Kingdom and New York, NY, USA, Cambridge University Press.

IPCC (2011). Summary for Policymakers. In: IPCC Special Report on Renewable Energy Sources and Climate Change Mitigation. O. Edenhofer, R. Pichs-Madruga, Y. Sokona, K. Seyboth, P. Matschoss, S. Kadner, T. Zwickel, P. Eickemeier, G. Hansen, S. Schlömer and C. v. Stechow, Eds. Cambridge, United Kingdom and New York, NY, USA, Cambridge University Press.

Irwin, D. A. and P. J. Klenow (1994). "Learning-by-Doing Spillovers in the Semiconductor Industry." Journal of Political Economy 102(6): 1200-1227.

Jaffe, A., R. G. Newell and R. N. Stavins (2005). "A tale of two market failures: Technology and environmental policy." Ecological Economics 54(2-3): 164-174.

Joskow, P. L. (2006). "Competitive Electricity Markets And Investment In New Generating Capacity. Working Papers 0609, Massachusetts Institute of Technology, Center for Energy and Environmental Policy Research."

Joskow, P. L. (2011). "Comparing the Costs of Intermittent and Dispatchable Electricity Generating Technologies." The American Economic Review 101(3): 238-241.

Junginger, M., W. van Sark and A. Faaij, Eds. (2010). Technological Learning In The Energy Sector. Lessons for Policy, Industry and Science. Cheltenham, Edward Elgar.

Kalkuhl, M., O. Edenhofer and K. Lessmann (2012). "Learning or Lock-in: Optimal Technology Policies to Support Mitigation." Resource and Energy Economics 34(1): 1-23.

Kalkuhl, M., K. Lessmann and O. Edenhofer (2013). "Renewable energy subsidies: Second-best policy or fatal aberration for mitigation?" Resource and Energy Economics 35(3): 217-234.

Knopf, B., H.-Y. Chen, E. De Cian, H. Förster, A. Kanudia, I. Karkatsouli, I. Keppo, T. Koljonen, K. Schumacher and D. P. van Vuuren (2013). "Beyond 2020 - Strategies for transforming the European energy system." Climate Change Economics(EMF28 special issue).

Knopf, B., O. Edenhofer, T. Barker, N. Bauer, L. Baumstark, B. Chateau, P. Criqui, A. Held, M. Isaac, M. Jakob, E. Jochem, A. Kitous, S. Kypreos, M. Leimbach, B. Magné, S. Mima, W. Schade, S. Scrieciu, $H$. Turton and D. van Vuuren (2009). The economics of low stabilisation: implications for technological change and policy. In: Making climate change work for us - ADAM synthesis book. M. Hulme and H. Neufeldt, Eds. Cambridge University Press.

Knopf, B., G. Luderer and O. Edenhofer (2011). "Exploring the feasibility of low stabilization targets." Wiley Interdisciplinary Reviews of Climate Change 2(4): 617-626.

Krey, V. and L. Clarke (2011). "Role of renewable energy in climate mitigation: a synthesis of recent scenarios." Climate Policy 11(4): 1131-1158.

Lamont, A. (2008). "Assessing the Long-Term System Value of Intermittent Electric Generation Technologies." Energy Economics 30(3): 1208-1231.

Leprich, U., E. Hauser and K. Grashof (2012). Kompassstudie Marktdesign Leitideen für ein Design eines Stromsystems mit hohem Anteil fluktuierender Erneuerbarer Energien. www.beeev.de/_downloads/publikationen/studien/2012/1212_BEE-GPE-IZES-KompassstudieMarktdesign.pdf. .

Luderer, G., V. Bosetti, M. Jakob, M. Leimbach, J. C. Steckel, H. Waisman and O. Edenhofer (2012). "The economics of decarbonizing the energy system - results and insights from the RECIPE model intercomparison." Climatic Change 114(1): 9-37.

Luderer, G., V. Krey, K. Calvin, J. Merrick, S. Mima, R. Pietzcker, J. Van Vliet and K. Wada (forthcoming). "The role of renewable energy in climate stabilization: results from the EMF27 scenarios." Climatic Change. 
Mai, T., J. Logan, N. Blair, P. Sullivan and M. Bazilian (2013). RE-ASSUME A Decision Maker's Guide to Evaluating Energy Scenarios, Modeling, and Assumptions. http://iea-retd.org/wpcontent/uploads/2013/07/RE-ASSUME_IEA-RETD_2013.pdf

Mai, T., R. Wiser, D. Sandor, G. Brinkman, G. Heath, P. Denholm, D. J. Hostick, N. Darghouth, A. Schlosser and K. Strzepek (2012). Exploration of High-Penetration Renewable Electricity Futures. Vol. 1 of Renewable Electricity Futures Study. NREL/TP-6A20-52409-1. Golden, CO: National Renewable Energy Laboratory. http://www.nrel.gov/docs/fy12osti/52409-1.pdf

McCollum, D. L., V. Krey and K. Riahi (2011). "An integrated approach to energy sustainability." Nature Climate Change 1(December 2011): 428-429.

McCollum, D. L., V. Krey, K. Riahi, P. Kolp, A. Grubler, M. Makowski and N. Nakicenovic (2013). "Climate policies can help resolve energy security and air pollution challenges." Climatic Change 119(2): 479-494.

Milligan, M., E. Ela, B. M. Hodge, B. Kirby, D. Lew, C. Clark, J. DeCesaro and K. Lynn (2011). "Integration of Variable Generation, Cost-Causation, and Integration Costs." The Electricity Journal 24(9): 5163.

Milligan, M. and B. Kirby (2009). "Calculating Wind Integration Costs: Separating Wind Energy Value from Integration Cost Impacts", NREL Technical Report TP-550-46275.

Mills, A. and R. Wiser (2012). Changes in the Economic Value of Variable Generation at High Penetration Levels: A Pilot Case Study of California. Ernest Orlando Lawrence Berkeley National Laboratory. http://www.csp-alliance.org/wp-content/uploads/2011/11/Changes-in-Economic-Value-ofVariable-Gen-at-High-Penetration-Levels.pdf.

Moomaw, W., F. Yamba, M. Kamimoto, L. Maurice, J. Nyboer, K. Urama and T. Weir (2011). Introduction. In: Special Report on Renewable Energy Sources and Climate Change Mitigation. O. Edenhofer, R. Pichs-Madruga, Y. Sokona, K. Seyboth, P. Matschoss, S. Kadner, T. Zwickel, P. Eickemeier, G. Hansen, S. Schlömer and C. v. Stechow, Eds. Cambridge University Press Cambridge, United Kingdom and New York, NY, USA.

Müsgens, F. (2013): "Equilibrium Prices and Investment in Electricity Systems with CO2-Emission Trading and High Shares of Renewable Energies", Paper presented at the Mannheim Energy Conference 24-25 June 2013.

Müsgens, F. and Peek, M (2011): "Sind Kapazitätsmärkte in Deutschland erforderlich? - Eine kritische Analyse vor dem Hintergrund der Ökonomischen Theorie." Zeitschrift für neues Energierecht (ZNER) 6/2011: 576-583.

Neij, L. (2008). "Cost development of future technologies for power generation-A study based on experiencecurves and complementary bottom-up assessments." Energy Policy 36(6): 2200-2211.

Nemet, G. F. (2009). "Interim monitoring of cost dynamics for publicly supported energy technologies." Energy Policy 37(3): 825-835.

Nicolosi, M. (2012a). The Economics of Renewable Electricity Market Integration. An Empirical and Model-Based Analysis of Regulatory Frameworks and Their Impacts on the Power Market, Universität zu Köln. PhD.

Nicolosi, M. (2012b). "Notwendigkeit und Ausgestaltungsmöglichkeiten eines Kapazitätsmechanismus für Deutschland". Kurzgutachten erstellt für das Umweltbundesamt. Ecofys GmbH. http://www.ecofys.com/files/files/ecofys 2012 kapazitaetsmechanismen.pdf

Nordhaus, W. D. (2009a). Designing a friendly space for technological change to slow global warming. Snowmass Conference on Technologies to Combat Global Warming, Snowmass (CO), August 3-4.

Nordhaus, W. D. (2009b). "The Perils of the Learning Model For Modeling Endogenous Technological Change." National Bureau of Economic Research Working Paper Series No. 14638. http://www.nber.org/papers/w14638.pdf 
Pahle, M., B. Knopf, O. Tietjen and E. Schmid (2012). Kosten des Ausbaus der Erneuerbaren Energien: Eine Metaanalyse von Szenarien. http://www.umweltdaten.de/publikationen/fpdf-I/4351.pdf

Palmer, K. and D. Burtraw (2005). "Cost-effectiveness of renewable electricity policies." Energy Economics 27(6): 873-894.

Pérez-Arriaga, I.J. (2001). Long-term reliability of generation in competitive wholesale markets: a critical review of issues and alternative options. IIT Working PaperIIT-00-098IT, June2001.

Pérez-Arriaga, I.J. and C. Meseguer (1997). "Wholesale marginal prices in competitive generation markets. " IEEE Transactions on Power Systems 12: 710-717.

Piscitello, L., P. Garrone and Y. Wang (2012). Cross-country spillovers in the renewable energy sector. Paper to be presented at the DRUID 2012 on June 19 to June 21 at CBS, Copenhagen, Denmark. http://druid8.sit.aau.dk/acc_papers/8sqn3os3fph4j08s4ic461g60k36.pdf

REN21 (2012). Renewables 2012 Global Status Report (Paris: REN21 Secretariat). http://www.map.ren21.net/GSR/GSR2012_low.pdf

Rodilla, P. and C. Batlle (2012). "Security of electricity supply at the generation level: problem analysis." Energy Policy 40: 177-185.

Rodrik, D. (2007). One Economics, Many Recipes: Globalization, Institutions, and Economic Growth, Princeton University Press.

Sathaye, J., O. Lucon, A. Rahman, J. Christensen, F. Denton, J. Fujino, G. Heath, S. Kadner, M. Mirza, H. Rudnick, A. Schlaepfer and A. Shmakin (2011). Renewable Energy in the Context of Sustainable Development. In: IPCC Special Report on Renewable Energy Sources and Climate Change Mitigation O. Edenhofer, R. Pichs-Madruga, Y. Sokona, K. Seyboth, P. Matschoss, S. Kadner, T. Zwickel, P. Eickemeier, G. Hansen, S. Schlömer and C. v. Stechow, Eds. Cambridge, United Kingdom and New York, NY, USA., Cambridge University Press.

Schmid, E., M. Pahle and B. Knopf (forthcoming). "A Meta-Analysis of Renewable Electricity Generation in German Mitigaiton Scenarios." Energy Policy.

Sensfuß, F., M. Ragwitz and M. Genoese (2008). "The merit-order effect: A detailed analysis of the price effect of renewable electricity generation on spot market prices in Germany." Energy Policy 36(8): 3086-3094.

Sims, R., P. Mercado, W. Krewitt, G. Bhuyan, D. Flynn, H. Holttinen, G. Jannuzzi, S. Khennas, Y. Liu, M. O’Malley, L. J. Nilsson, J. Ogden, K. Ogimoto, H. Outhred, Ø. Ulleberg and F. v. Hulle (2011). Integration of Renewable Energy into Present and Future Energy Systems. In: IPCC Special Report on Renewable Energy Sources and Climate. O. Edenhofer, R. Pichs-Madruga, Y. Sokona, K. Seyboth, P. Matschoss, S. Kadner, T. Zwickel, P. Eickemeier, G. Hansen, S. Schlömer and C. v. Stechow, Eds. Cambridge University Press, Cambridge, United Kingdom and New York, NY, USA.

Smith, C., M. Milligan, E. DeMeo and B. Parsons (2007). "Utility Wind Integration and Operating Impact State of the Art." IEEE Transactions on Power Systems 22(3): 900-908.

Stiglitz, J. E. (1990). Whither Socialism?, MIT Press.

Stoft, S. (2002). Power System Economics: Designing Markets for Electricity. IEEE Press.e

Stoughton, M., R. Chen and S. Lee (1980): "Direct construction of the optimal generation mix." IEEE Transactions on Power Apparatus and Systems 99(2): 753-759.

Sullivan, P., V. Krey and K. Riahi (2013). "Impacts of Considering Electric Sector Variability and Reliability in the MESSAGE Model." Energy Strategy Reviews 1(3): 157-163.

Tavoni, M., E. Cian, G. Luderer, J. Steckel and H. Waisman (2012). "The value of technology and of its evolution towards a low carbon economy." Climatic Change 114(1): 39-57.

Ueckerdt, F., L. Hirth, G. Luderer and O. Edenhofer (2013). System LCOE: What are the costs of variable renewables? USAEE Working Paper 2200572. http://ssrn.com/abstract=2200572

Ulph, A. and D. Ulph (2009). Optimal Climate Change Policies When Governments Cannot Commit. Discussion Paper 0909, University of St. Andrews. 
UNEP (2011). "Towards a Green Economy: Pathways to Sustainable Development and Poverty Eradication - A Synthesis for Policy Makers." www.unep.org/greeneconomy

Verbruggen, A., W. Moomaw and J. Nyboer (2011). Annex I: Glossary, Acronyms, Chemical Symbols and Prefixes. In: IPCC Special Report on Renewable Energy Sources and Climate Change Mitigation. O. Edenhofer, R. Pichs-Madruga, Y. Sokona, K. Seyboth, P. Matschoss, S. Kadner, T. Zwickel, P. Eickemeier, G. Hansen, S. Schlömer and C. v. Stechow, Eds. Cambridge University Press, Cambridge, United Kingdom and New York, NY, USA.

Yeh, S. and E. S. Rubin (2012). "A review of uncertainties in technology experience curves." Energy Economics 34(3): 762-771.

You, C. F. and X. C. Xu (2010). "Coal combustion and its pollution control in China." Energy 35(11): 44674472 . 
Figures in Black and White

2030

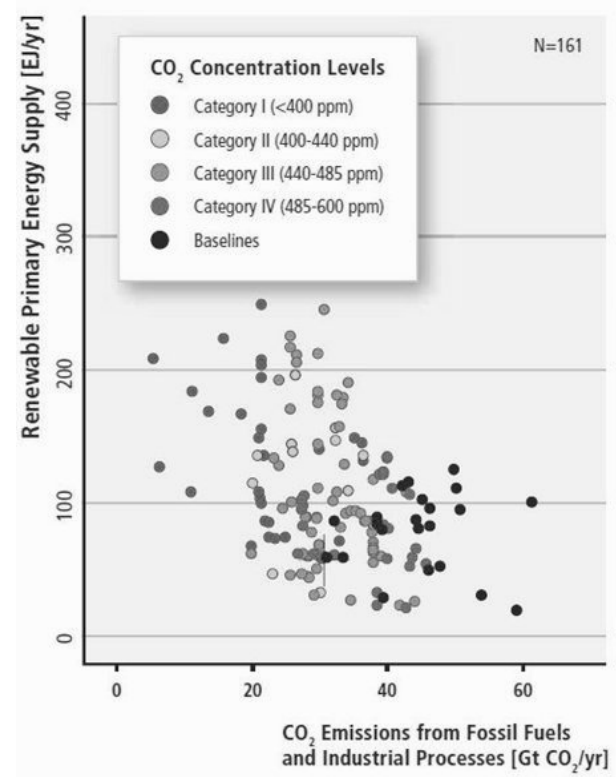

$N=161$

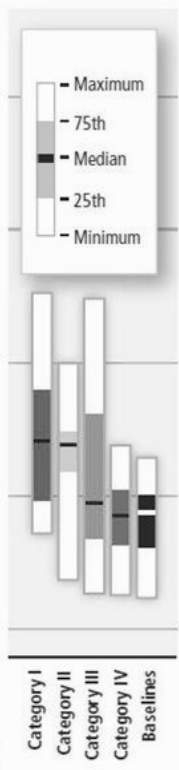

2050

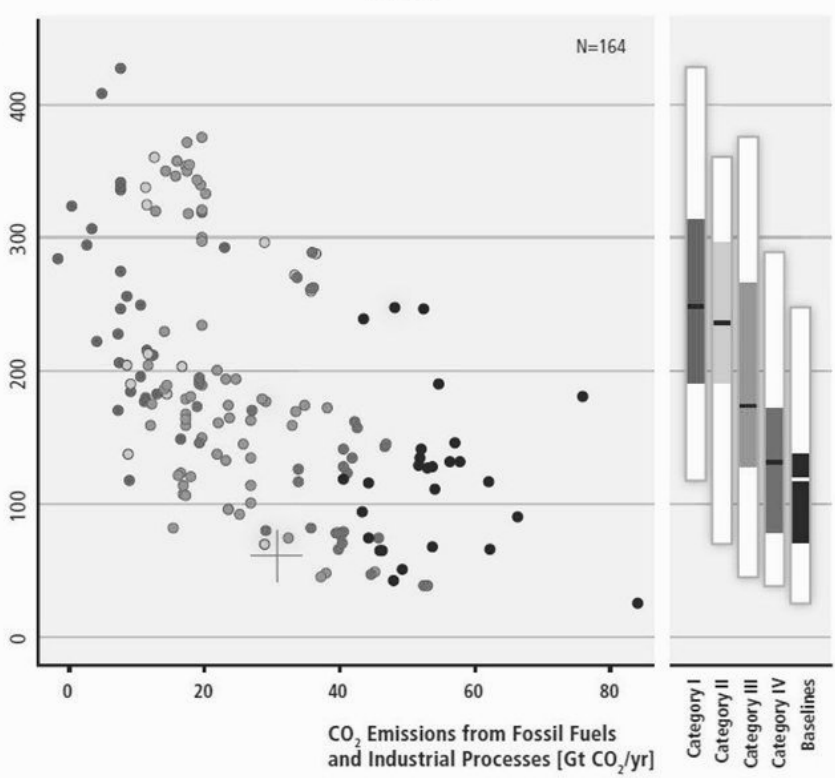

Figure 2. Estimates of the economic potential of RE sources in terms of global renewable primary energy supply (direct equivalent) plotted against $\mathrm{CO}_{2}$ emissions from fossil fuels and industrial processes from 161 and 164 model-based, long-term mitigation scenarios in the years 2030 and 2050 for different mitigation scenarios and the baseline, respectively. Crosses indicate the relationship in 2007. Source: Figure SMP.9 in IPCC (2011).

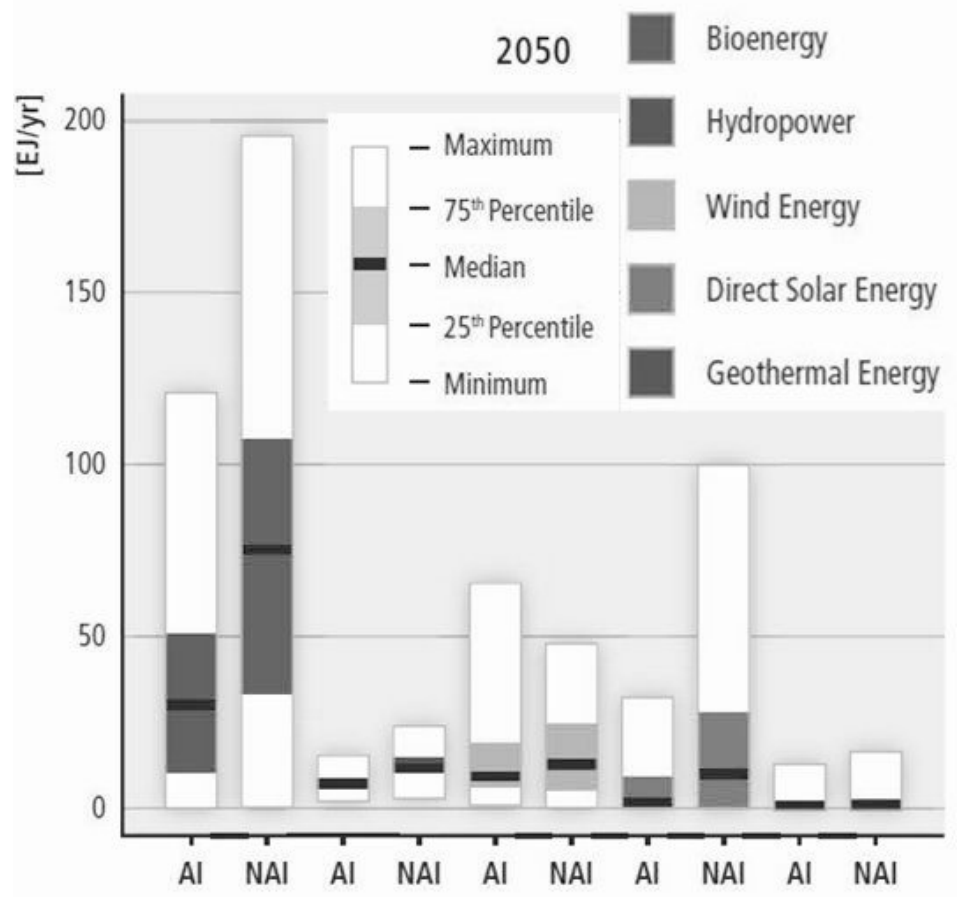

Figure 3. Distribution of global primary energy supply (direct equivalent) in Annex I (AI) and Non-Annex I (NAI) countries by source, across all scenarios for the year 2050. Based on Figure 10.8 in Fischedick et al. (2011). 


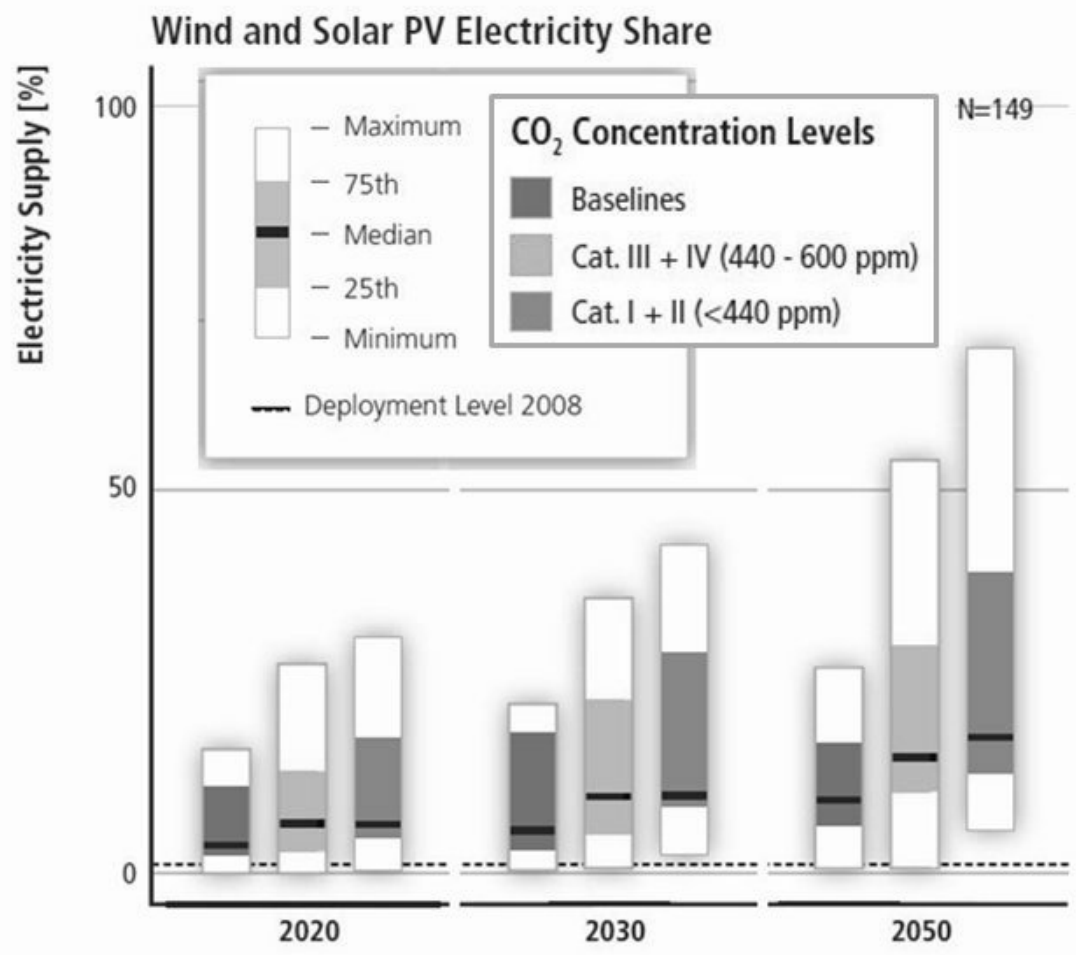

Figure 4. Share of wind and solar photovoltaic (PV) in electricity production in different mitigation scenarios. Based on Figure 10.9 in Fischedick et al. (2011).

Global, 2005-2100

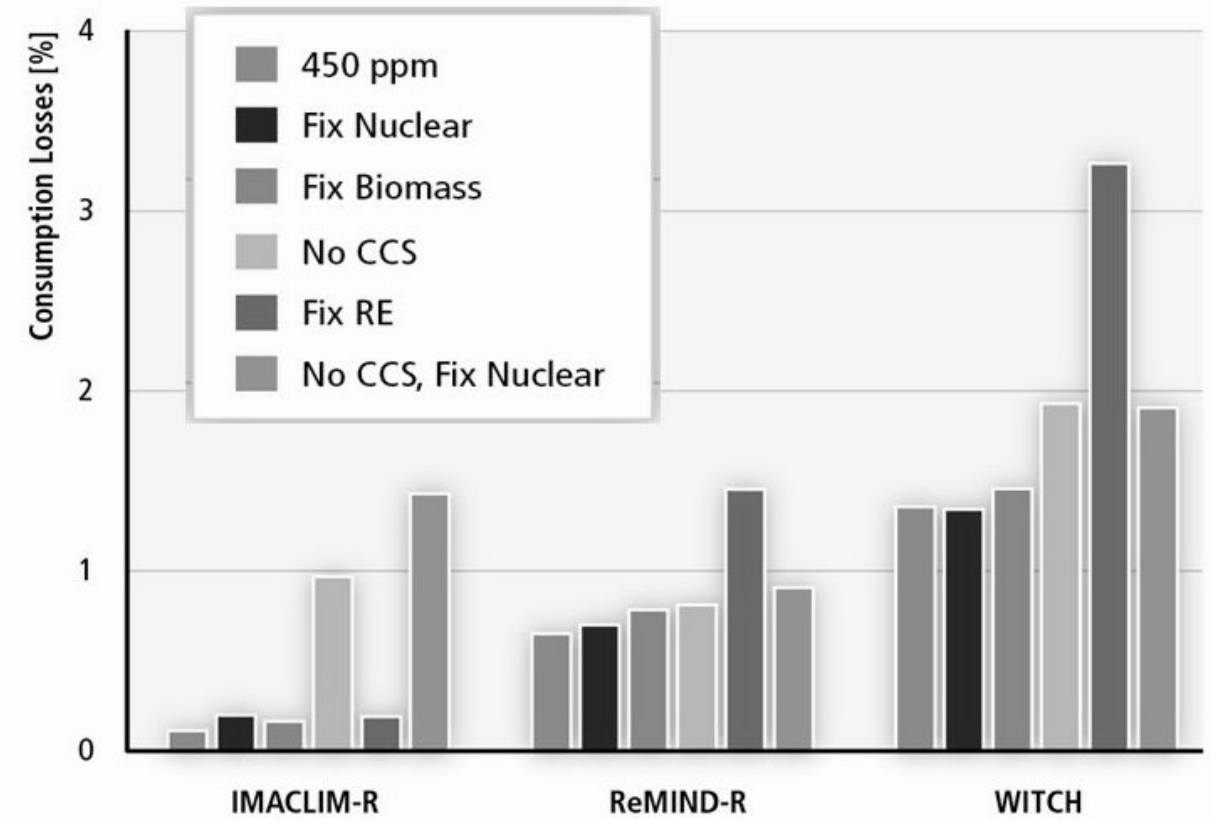

Figure 5. Aggregated global consumption losses from 2005-2100 relative to the respective baseline scenarios in the RECIPE project. The numbers are given for the default setting of $450 \mathrm{ppm}$ with full technology availability, as well as for scenarios with only limited availability of technologies. The discount rate is $3 \%$. Source: Based on Figure 10.12 in Fischedick et al. (2011). 